\title{
Accusative Case-Assignment in Double Object Constructions in Standard Arabic: A Minimalist Approach
}

\author{
Mostapha Thabit Mohamed ${ }^{1}$ \\ ${ }^{1}$ Department of English, Faculty of Arts, Minia University, Egypt \\ Correspondence: Mostapha Thabit Mohamed, Department of English, Faculty of Arts, Minia University, Egypt. \\ E-mail: mostapha.thabit6@gmail.com
}

Received: September 3, 2013

Accepted: October 24, 2013 Online Published: December 31, 2013

doi:10.5539/ass.v10n1p95

URL: http://dx.doi.org/10.5539/ass.v10n1p95

\begin{abstract}
The study investigates the issue of Double object constructions (DOCs) in Standard Arabic (SA). The investigation is conducted within the framework of Chomsky's Minimalist Program (MP) $(1995,2000,2004)$, and Radford's proposals of accusative - case assignment $(2004,2009)$ in DOCs. The study aims to provide an account for two objectives. The first objective is to show how DOCs in SA are derived within MP. The second objective is to justify how accusative case is assigned to the first and second objects of these constructions. To achieve the first objective, the study shows that the structure of DOCs in SA can be derived by the adoption of the VP shell, one of the principles of MP, as introduced by Chomsky $(1995,2000,2004,2005,2007,2008)$. The analysis of VP in SA reflects the fact that in DOCs the main verb has the first object as its specifer and the second object as its complement. The adoption of Radford's proposals $(2004,2009)$ provides a solution for the second objective of the study, the accusative - case assignment in DOCs in SA. According to Radford' proposals, the first object is assigned the accusative case by the accusative light- $v$ whereas, the second object checks its accusative case against that of the main V. The study suggests further research on the application of MP principles on other linguistic features of SA.
\end{abstract}

Keywords: minimalist program, double object constructions, case-assignment in Arabic, double object constructions in Arabic

\section{Introduction}

There are certain verbs in Arabic that are followed by two noun phrases (NPs). The former NP1 functions as the first object and the latter NP2 functions as the second object. Both NPs in these constructions in Arabic are assigned the same accusative case (Hasan, 1974) and these constructions are known as double object constructions (DOCs).

The purpose of this study is to investigate DOCs in Standard Arabic (SA), which is a variety of Arabic language used in formal written or oral discourse (Badawi, Carter \& Gully, 2004; al-Batal, 1990). The analysis conducted in this study addresses two issues. The first issue is to provide an account for the derivation of DOCs in SA and their underlying structure. The second issue is to present an explanation for the accusative case which is assigned to the two objects in these constructions.

To find answers for these two issues the analysis of DOCs in SA is introduced within the framework of Chomsky's Minimalism Program (MP) and its basic principles such as VP shell, merger, agreement features and c- command, as outlined in Chomsky (1995) and developed later on in his subsequent works $(2000,2004,2005$, 2007). The study attempts to show how far MP can provide an adequate analysis for the derivation of DOCs and how the first and second objects are assigned accusative case in these constructions.

Many studies have been introduced within the framework of MP that discuss different features of Arabic language. Shorafat (1998) introduced an Agree-based model for the analysis of the structure of Arabic clauses. Mahfoudhi (2002) provides an account of the word order variation in both Standard and Tunisian Arabic under the principles of MP. Galal (2004) discusses the structure of the relative clause in Modern Standard Arabic by the application of the principles of MP. Soltan $(2006,2007)$ discusses the word order and the asymmetry of subject-verb agreement in SA in terms of agree-based minimalist syntax. Horias (2009) presents a minimalist approach to the feature of agreement in Arabic. Al-Momani (2010) adopts a minimalist approach to analyze the 
relativization of the direct object relative clauses in Jordanian Arabic. Assiri (2011) accounted for the agreement (a) symmetries between nouns and adjectives in Modern Standard Arabic with the application of agre-based approach.

Despite the fact that the studies surveyed above dealt with different linguistic features of SA under the principles of MP, none of these studies dealt with the linguistic features of DOCs, their derivation or the assignment of accusative case to the objects of these constructions.

\section{Problem of the Study}

There are verbs in SA that are followed by two NPs which are assigned the same accusative case. The NP that immediately follows the verb is traditionally called the first object, NP1 while the internal NP is called the second object, NP2 (Hasan, 1974, p. 177). The present study explains how these two NPs are assigned the same accusative case.

The study encounters two problems. The first problem is to explain how DOCs in SA are derived and justified by the application of MP principles such as VP shell, merger, agreement and c-command. The second problem is to identify the accusative case assigners that assign the accusative case to both NP1 and NP2 in these constructions. The study discusses two options for case-assignment in DOCs in SA. The first option discusses the possibility that we have only one case assigner that assigns accusative case for both the first and the second NPs. The second option investigates the possibility of having two different accusative case assigners for these two NPs.

The study attempts to provide answers for the following questions:

1) Does MP provide an adequate explanation for the derivation of DOCs in SA?

2) Does MP provide an adequate explanation for accusative case - assignment for the first and the second objects in SA?

\section{Double-Object Constructions in Standard Arabic}

A DOC is a clause which contains a verb that is followed by two NPs complements. The NP1 that immediately follows the verb is traditionally called by Arab grammarians the first object, which is equivalent to the indirect object in English. The NP2 is traditionally referred to as the second object (Hasan, 1974), which is equivalent to the direct object in English. This can be shown in the following example: (Hasan, 1974, p. 177)
1- ?a?Tyat-u
?al-walad-a
wardat-an.
NP1
NP2
give. I 1s-Nom
the-boy-Acc.
a flower-Acc.

"I gave the boy a flower."

The example shows that the verb "?a?Ta" is followed by two objects, ?al-walad-a, which is the first object and wardat-an, which is the second object. Both objects have the same accusative case and carry objective morphological markings, "-a" for the first object and "an", for the second object.

The canonical order for the two NPs is that NP1 must precede NP2. Arab grammarians have justified this canonical order on a semantic reason. In example (1), NP1 is the receiver of the action introduced by the verb ?a?Ta", accordingly it is considered as (the semantic Subject), " faa?il fi ?al-ma?na". The Np2 is known as "maf?ul fi ?al-ma?na", (the semantic object), as it is affected by the action of the semantic subject (Hasan, 1974).

Despite the numerous studies whish have analyzed different features and constructions of SA, as shown in the introduction, no study has ever dealt with derivation and accusative case-assignment in DOCs in SA. Moreover, traditional Arab did not explain how to derive DOCs or to justify the canonical order of the two objects (Hsan, 1974; ?ibn ?ukeel, 1990). When the first object precedes the second object that will give a grammatical clause, as shown in (1). However, when the second object precedes the first object, this will give an ungrammatical clause, as shown in (2):

$\begin{array}{ccc}* 2-? \text { a } \text { Tyat-u } & \text { wardat-an. } & \text { ?al-walad-a } \\ \text { NP2 } & \text { NP1 }\end{array}$

"I gave a flower the boy."

\section{Basic Principles of Minimalism}

MP regards language as an economical design that should be explained in a minimal number of principles. 
Chomsky (1995) introduced what is known as "optimal theory" with "the goal to have very general economy principles" (Chomsky 1995). This principle of "economy" requires that each syntactic derivation should involve grammatical operations "as few as possible" (Radford 2009, p.335).Accordingly, optimality has been achieved by dropping out principles such as D-structure, S-structure, X Bar theory and Binding condition (Lasnik, 2003; Hornstein et al., 2005; Boecks, 2006)

To provide an explanation for DOCs, Chomsky (1995) has introduced MP principles such as "agreement", "vp shell" and "c-command". These principles help to explain the process of deriving constructions such as DOCs which were previously considered as problems and represent challenges for the Generative Theory (Radford 1997, 2004, 2009).

One of the basic principles embodied in MP is VP shells. All constructions within the framework of MP are basically derived as having VP shells structures (Radford, 2004, 2009). The traditional VP structure which contains the verb and its two complements, as in DOCs, becomes a subordinate to vp and is attached to a higher v. The small v, which is called light verb, is defined in MP as abstract in nature. Light verb is spelled out as an accusative verb because it has the same causative representation of the verb MAKE (Chomsky, 1995; Radford, 2004, 2009). Moreover, the light verb, as stated by Chomsky (2006), is a strong affix and hence can trigger movement of the lexical verb to adjoin it.

Chomsky (1995) has suggested that the transitive light verb which carries fie- features of person and number can assign accusative case to a constituent which it c-commands. The abstract transitive light-verb can act as a probe that assigns the accusative case to the goal it c-commands (Radford, 2004, 2009 for more discussion).

Another basic operation in MP is Agree. Agree is defined as the relationship that exists between a probe and a goal that exists in its c-commanding domain (Chomsky, 1995; Radford, 2004, 2008). Agree has a basic role to play in case-assignment. As stated in MP, a goal has unvalued case which needs to be valued and checked. Due to the fact that this goal is c-commanded by a probe that has valued case, the unvalued case of the goal is checked and valued against the valued case of the probe which c-commands it. In other words, when agreement exists between a probe and a goal in its c-commanding domain, the probe probes this goal and values its unvalued case. On the other hand, the goal values the unvalued features of person and number of the probe.

C-command has its central role to play in the derivation processes of all constructions within MP. Almost all "syntactic relations used in linguistic description are limited to the relation of c-command" (Radford, 2009, p. 281) For instance, all operations of case assignment, checking features, deletion of uninterpretable features, and movements to heads specifiers positions are allowed by c-command (Chomsky,1995, 2000, 2004; Radford, 2009).

The three principles of VP shell, Agree and c-command are interrelated in the process of derivation and case-assignment in English. The following sections will show how these interrelated principles help to derive DOCs and help to justify the accusative case-assignment for the NP1 and NP2 in these constructions.

Several studies have been conducted to account for the underlying structure and case-assignment of DOCs in English language. Larson (1988) assumes that DOCs are derived from a process that is called Dative Shift, a process that is similar to that of passive formation. According to Larson, the following sentence, (his, 1.b, p.335):

3- John sent Mary a letter.

is derived from (4) by the application of Dative Shift,(his,1.a, p. 335)

4- John sent a letter to Mary.

The derivation of (3) is achieved proceeds as follows:

1) the case assigned to the indirect object by the preposition to in (1) is absorbed.

2) the indirect object is raised into the specifier position of the lower VP in order to receive case.

3) the verb send moves into the empty V position in the upper VP where it assigns case to the VP subject, giving the surface form:

4) the direct object is assigned as a v' adjunct.

This derivation can be shown in the following diagram: (Larson, p. 335, his 26). 
$5-$



Moreover, Larson (1990) provides an answer to the question of how accusative case is assigned twice in DOCs, where both the direct and the indirect object have the same case. He proposes that there are two types of accusative cases assigned to the two arguments in a DOC: one is structural and the other is inherent. The structural objective case is assigned to the verb when it is governed by $\{$ infl, $\mathrm{V}\}$ whereas, the inherent objective case is assigned as a pure lexical property of V (p. 360).

However, the proposal of Larson (1990), as outlined above, suffers problems such as the treatment of modifiers and arguments are structurally indistinguishable and cases of subject 0-role assignment (Jackendoff, 1999)

Another analysis of DOCs in English is conducted within the framework of the early version of MP is introduced by Radford (1997). He assumes a kind of Larsonian VP shell analysis for the derivation of DOCs. He assumes that the VP shell provides a straightforward account for the derivation of DOCs. Based on this assumption, the structure of a sentence such as the following (Radford, 1997, p. 444):

6- The crew handed back the passengers their passports", has the following underlying structure:

$7-$

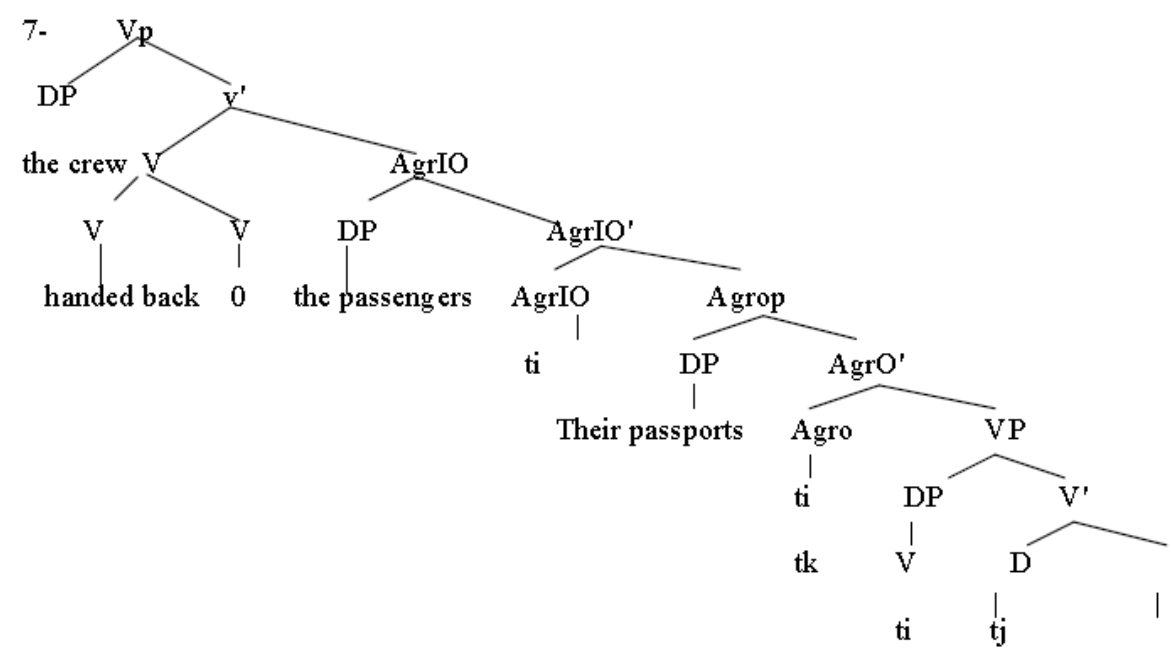

The derivation goes as follows. The verb "handed back" moves to AgrOp and the NP "their passports" is raised to the specifier position of AgrOP. Since the NP and the verb are now in a Spec-head relation, the objective case feature carried by each can be checked by the other. The verb, then moves to AgrIO followed by the NP the passengers which raises to [Spec, AgrIOP] where it can check its dative-case- feature against that of the verb 
under a spec-head configuration.

However, Radford's Agr-based analysis suffers a number of shortcomings. First, the Spec-head feature agreement has a problematic effect as it fails to justify agreement feature based on spec-head relationship in sentences such as the following example (Radford, 2009, p. 281):

8- There were awarded several prizes.

a spec-head account of agreement fails to account for agreement between the auxiliary "were" and the nominal "several prizes" .The auxiliary "were" occupies the head T position of TP in (1) and the expletive pronoun "there" is in spec-T, a spec-head account of agreement would lead us to expect that "were" should agree with "there". But instead, "were" agrees with the in situ complement "several prizes."

Second, Radford's Agr-based analysis violates the Economy Condition which minimizes the number of syntactic operations applied in derivations and representations and requires that there should be" no superfluous steps in derivation" (Chomsky, 1989 p.69.) In the above example, the verb takes superfluous movements in order to check its case features. First, the verb moves to AgrOP, then to Agro IOP and finally to v. In addition, the verb, following that manner, has multiple accusative case-assignment that is assigned to two different NPs, one is the indirect object whereas, the other is the direct object.

To overcome the problem of case-assignment in DOCs within MP, Ura (2000) suggests that the verb in DOCs allows multiple checking of its case feature. According to Ura, the accusative- case feature of the verb is $[+$ multiple]. He states that "The [+multiple] Fs of the verb must undergo more than one feature-checking operation, and, hence, they can or must enter into more than one checking relation" (Ura, 2000, p.17). According to Ura's suggestion, the accusative cases are checked by an appropriate functional head in the Spec of that head. The verb is raised up first to AgrOP where it can check its accusative against that of the theme under Spec-head configuration. Since the accusative case- feature is [+multiple], it is not deleted. The verb has to check its accusative case again in order to satisfy this property. It is therefore raised up to AgrIOP where it can check its accusative case-feature against that of the goal under a Spec-head relation.

Ura's (2000) suggestion of accusative case-assignment is almost the same as Radford's (1997) proposal, as discussed above, and has the same drawbacks. To check its case feature against its internal argument, the verb has to move up to two positions where its multiple case-features are checked. It moves first to AgrOP to check case against that of the theme and then moves up to AgrIOP where it checks its case against that of the goal. As a result, the Economy Condition is violated as we have superfluous steps in derivation. The verb moves first AgrOP then moves up to AgrIOP to check its multiple cases-features.

Radford (2004) introduces two alternative analyses for the explanation of accusative case-assignment in DOCs in English. His first analysis (2004), is based on the concept of the "transitive light verb", which is introduced by Chomsky (1995). He argues that the transitive light-verb is responsible for accusative case-assignment. Radford hypothesize that accusative case is assigned by the "transitive light verb" to an NP that it c-commands in probe-goal relationship. In the following example (his, 91, p. 274):

9- You have upset them.

The verb "upset" is merged with its abstract complement "THEY" to form "upset THEY". The pronoun has valued (interpretable) features of third-person, singular-number and unvalued (uninterpretable) case-feature. The resulting VP is merged with a null transitive light-verb forming v-bar. The transitive light-verb carries valued feature of case and unvalued features of person and number, as the following diagram shows:

$10-$

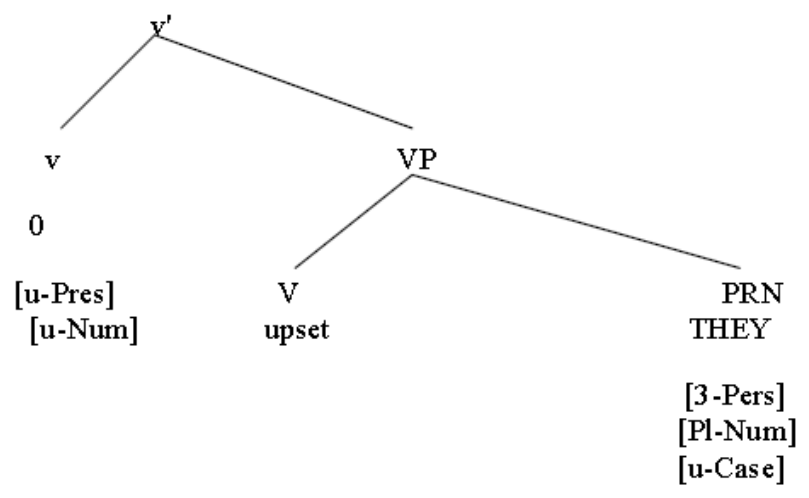


The null light-verb c-commands the pronoun "THEY" which has unvalued features. As a result, the null light-verb probes "THEY" as an active goal. The unvalued feature of case of the goal is valued by the probe transitive light-verb to become "them", and the unvalued features of person/ number of the accusative light-verb are valued by the goal "THEY" (Radford, 2004).

According to the above analysis, Radford shows that the accusative light-verb assigns an accusative case to its complement in simple clauses.

However, in a recent analysis of accusative case-assignment Radford (2009) states that V itself, not the accusative light-verb can assign accusative case to its complement. This can be shown in the following example (his 44, p. 304):

11- He has arrested them

T probes with the goal "HE", values its unvalued case as nominative "he" and triggers it to move to spec-T. The question which is raised by Radford is how the pronoun "them" has acquired its accusative case. Following the argument suggested by Radford (2009), the verb "arrested" with its theme complement "them" forms V' that merges with the agent "HE" to form the VP "he arrested them". Then, the resulting VP is merged with T to form $\mathrm{T}^{\prime}$. This can be shown in below:

$12-$

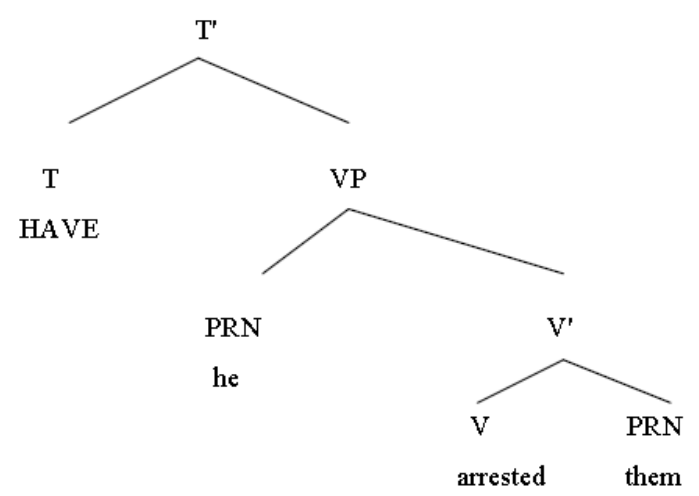

As the figure shows, T probes the pronoun "he" as its goal to value its unvalued features of person and number. However, as the diagram shows, $\mathrm{T}$ also can probe the complement "them" as its goal, but cannot agree with it. Radford provides two reasons that prevent $\mathrm{T}$ to probe with the goal "them". One reason is that the pronoun "them" already has its case-feature valued as accusative and deleted, and so will no longer be active for case/agreement operations.

The second reason is that the T-have probes the closest goal which is the subject "he". Since "he" can value all the unvalued agreement features on $\mathrm{T}$, there is no need for $\mathrm{T}$ to probe any further, in accordance with the Economy Condition. (Radford, 2009, p. 204)

Radford's two analyses of accusative case-assignment reflect major suggestions that can be summarized as follows:

1) There are two accusative case-assigners in MP, the accusative light-verb and the lexical transitive verb.

2) The light-verb is transitive and so it assigns accusative case to the agent it c-commands.

3) The transitive lexical verb has only one accusative case that it assigns to its complement NP which it c-commands.

4) The processes of accusative case-assignment are constrained by the Economy Condition.

Radford's analysis of accusative case-assignment conducted within the principles of MP will be adopted in this study to the analysis of DOCs in SA. Radford's suggestion that accusative case can be assigned to NPs either by a lexical transitive verb or by the accusative light-verb $(2004,2009)$ can be extended to provide an analysis for the problem of accusative case-assignment in DOCs in WA. If we assume that the two analyses introduced by Radford, as surveyed above, are subsumed in the following principles:

13-a- the transitive verb assigns an accusative case to DP2, which is the complement of VP.

b- the accusative light-verb assigns an accusative case to NP1, which is the specifier of VP.

These principles supplemented by MP principles of c-command, merger, movement and agreement will be 
adopted to explain accusative case-assignment in DOCs

\section{Analysis of DOCs in SA.}

\subsection{Derivation of DOCs in $S A$}

The analysis of DOCs within the framework of MP is based on VP-Internal Subject Hypothesis which is introduced first by Larson (1988). The hypothesis states that the subject of the simple clause is generated as the specifer of the VP whereas, the main object is generated as the complement of the verb. Chomsky (1995) and Radford (1997, 2004, 2009) adopt this hypothesis to account for the analysis of DOCs in English, but with modification.

First, Chomsky (1995) refuses the proposal that DOCs are derived by the process of Dative Shift, a process that he introduced in his early works $(1955,1975)$, and suggests that DOCs are base generated. Second, he introduces modifications to Larson's VP-Internal Subject Hypothesis to justify the structure of DOCs in English. Instead of having the subject of the clause in the specifier position of VP and the object as the complement of the verb, Chomsky proposes that the indirect object (IO) functions as the specifer of VP and the direct object (DO) functions as the complement of VP. This can be shown in the following diagram:

$14-$

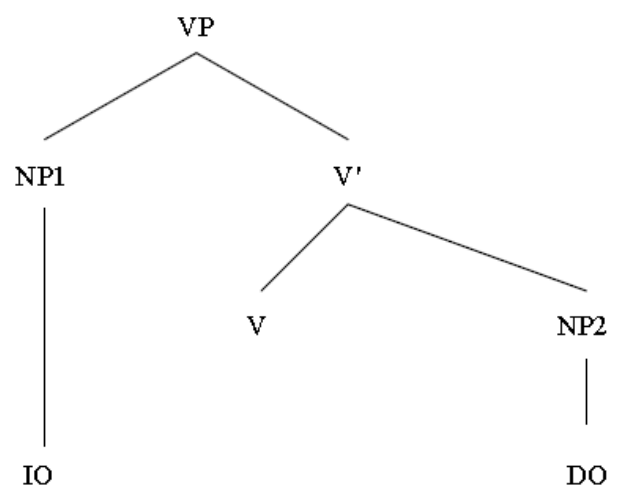

The proposal of Chomsky, as outlined above, is adopted to analyze not only DOCs but are extended to explain the structures of many other constructions in English (Radford, 2004, 2009).

The modified VP structure introduced by Chomsky can successfully provide an account for DOCs in SA. With the assumption that the structure of VP consists basically of a specifer and a complement, it can be said that the first object (NP1) is base-generated as the specifer of the VP and the second object (NP2) is base-generated as the complement of the main lexical verb. As a result, is a sentence as the following:

15- ?a?Tyat-u

give. I 1s-Nom ?al-walad-a

NP1 wardat-an.

NP2

"I gave the boy a flower."

The structure of the VP can be something as the following:

$16-$

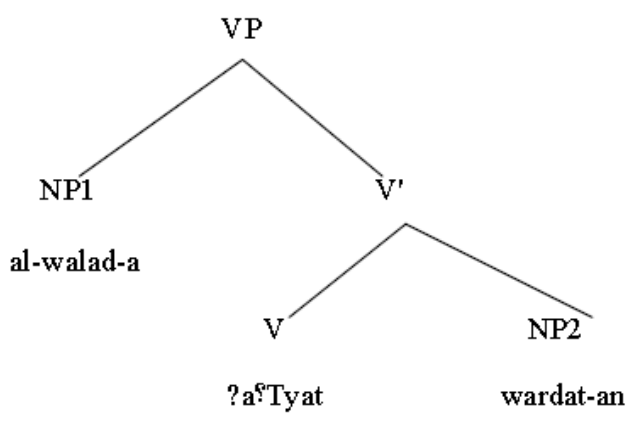

The view that VP of DOCs in SA are base generated the first object as its specifier and the second object as the complement of the main verb helps to introduce an account for the accusative case-assignment for both the first 
and second objects in these constructions, as will be discussed in (6.2).

\subsection{Case-assignment of DOCs in SA}

As mentioned above, the DOCs refer to the verb that is followed by two NPs that have the accusative markers, $\mathrm{a} a / \mathrm{an} "$ and function as objects. The difference between these two NPs is that the NP1 functions as the goal of the action, whereas the NP2 functions as the theme of the action.

The point to be tackled is to investigate how the NP2 checks its accusative case taking into consideration the assumption that verbs have only one accusative to be checked. When the verb in a DOC values its accusative case against that of the theme, then it is deleted. The deletion of the case feature of the verb results in causing the derivation to crash because the case feature of the goal will be visible to PF because it is still unvalued.

The application of Radford's principles, as outlined in (13-a-b), can provide an explanation for the accusative case-assignment in DOCs in SA. In the following example:

\begin{tabular}{|c|c|c|c|}
\hline 17- ?a?Ta & ?al- mu؟lem-u & $\begin{array}{c}\text { aTTalib-a } \\
1\end{array}$ & $\begin{array}{c}\text { kitaab-an } \\
2\end{array}$ \\
\hline
\end{tabular}

give- def. teacher.nom.s.mas def.student.acc.mas. book-acc.

- The teacher gave the student a book.

the V "?a?Ta" is merged with the second object "kitaab-an" to form the V-bar "?a?Ta kitaab-an" and this is then merged with the first object "aTTali-a" to form the VP structure, as shown below:

$18-$

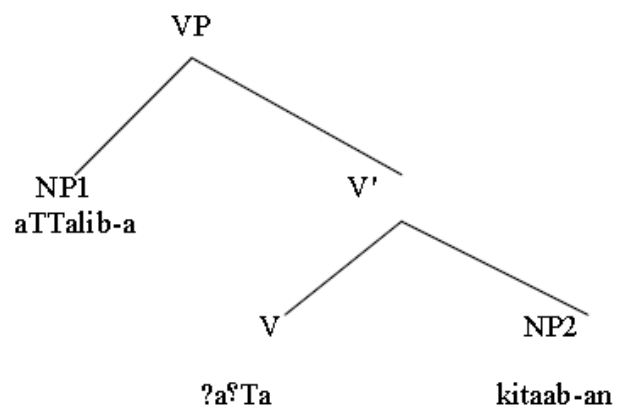

The V exists in the head position of the VP, whereas, the first object acts as the specifier of the VP and the second object functions as the complement of the V. It can be observed that the V c-commands DP2, but it is impossible to c-command NP1.

The resulting VP is then merged as a complement with the abstract causative light verb (v). As the causative light verb is affixal in nature, the $\mathrm{V}$ "?a?Ta" is raised to it to form the v-bar. The resulting v' is then merged with the subject "?al- mu?lem-u" to form vP:

$19-$

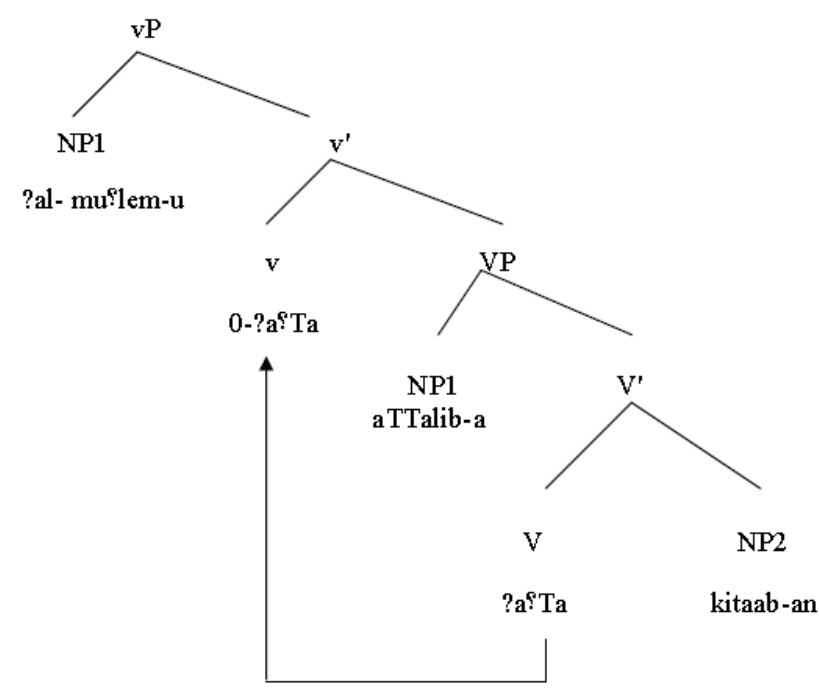


Since the main topic of this paper is the accusative case-assignment in SA and how the two NPs in the above figure are assigned accusative case, the analysis will be limited only to the structure of the $\mathrm{vP}$ as shown above (Mohammed, 1999; Soltan, 2007, for complete derivations of SA within MP).

According to the principles of MP, the range of syntactic relations of case-checking assignment should be limited to the relation of c-command (Radford, 2009). The diagram (19) shows that NP2 is c-commanded by the transitive verb "?a?Ta" so, its accusative case feature is valued against that of the verb. However, the accusative light-verb is in Spec of VP and can probe the NP1 as a goal and can also assign accusative case to it. According to this situation, we have two accusative case assigners to NP2. The first accusative case assigner is the transitive verb "?a?Ta" and the second accusative case assigner is the light-verb. Which one of both can be the case assigner for NP2?

There are three reasons that exclude the light $\mathrm{v}$ to be the assigner of accusative case to NP2. The first reason is due to the "The Defective Intervention Constraint" stated by Chomsky (2001, p.123). This constraint states that the probe has only one goal and rules out any probe which has more than one goal. As a result, the light-verb cannot take the NP2 as its goal and to value its unvalued its accusative case. The second reason is that the light v, as will be explained later, has as a goal NP1 which is closer to it than NP2. The third reason is that since the light-v has one accusative case which it can value against the unvalued accusative case of the its close goal NP1, accordingly, it has no other accusative case feature to be checked against any other goal found in the same construction.

The second argument to raise is concerned with the accusative case-assignment for the NP1 and the case assigner for that accusative case. The diagram (17) shows that the NP1 "aTTalib-a" which is the goal, is in the Spec position of the VP, whereas the transitive verb "?a?Ta", which is the probe, is the head of VP. The problem here is that the goal "NP1" c-commands the probe "?a?Ta" not vice-verse, which is not allowed by the principles of the MP. The probe should c-command its goal to value its Phie features of person and number, and in a reflexive operation, the c-commanded goal should value its case against its probe.

As the transitive verb "?a?Ta" is not in a position to be the probe of the NP1 "aTTalib-a", the NP1 should search for a c-commanding probe to value its accusative case that it carries. The only candidate that can probe the goal "NP1 is the accusative light-verb "v" which is the head of the $v^{\prime}$. The accusative light verb can function as the probe for the goal NP1 for two reasons. First, it c-commands the NP1 where the NP1 is in the Spec of the VP, the transitive light verb is in a higher position, as the head of $\mathrm{v}$, as the diagram shows. The second reason is that the light verb, as a probe, carries the feature of "accusative" that should be checked against the c-commanded NP1. Furthermore, both the probe and the goal are active as they have unvalued features that should be valued and then be deleted. As a result, the accusative light-verb values the unvalued feature of case on the goal as accusative.

To sum up, it can be concluded that the accusative case of DOCs in SA is assigned in two different ways. The accusative light-verb probes the NP1, the indirect object, as its goal and assigns its accusative case to it. The NP2, the direct object is assigned the accusative case by the c-commanding verb.

\section{Conclusion}

The present study has discussed DOCs in SA. The discussion has been conducted within the framework of Chomsky's MP. The study has discussed two issues. The first issue is the derivation of DOCs in SA. The second issue is the accusative case-assignment of the first and second objects in DOCs. The study has based its analysis of these two issues on Chomsky's MP and Radford's proposals, as outlined in (2004, 2009). As the study shows, DOCs in SA can be derived by the adoption of the VP shell, as introduced by Chomsky $(1995,2000,2001)$. The structure of VP shell in SA can have the first object as its specifer and the second object as its complement. Following that way, the verb does not c-command the first object and it is impossible to c-command it in any process of derivations. Meanwhile, the verb c-commands the second object as its complement.

The accusative case-assignment in DOCs in SA can be justified by Radford's principles. As the first object is in Spec position of VP, it is not c-commanded by the verb. For this reason, the first object values its unvalued accusative case by the light - verb, not the main V. The Second object values its accusative case against that of its c-commanding V. Thus, it can be concluded that in SA, the first object is assigned accusative case by the accusative light-v whereas, the second object checks its accusative case against that of the main lexical V.

\section{References}

Al-Batal, M. (1990). Connectives as cohesive elements in a modern expository Arabic text. In M. Eid, \& J. McCarthy (Eds.), Perspectives on Arabic Linguistics II (pp. 234-266). Amsterdam/Philadelphia: John 
Benjamins.

AL-Momani, I. (2010). Direct object relative clauses in Jordanian Arabic: A Minimalist Approach. International Journal of Academic Research, 2(3), 1010.

AL-Shorafat, M. (1998). The Minimalist program and the structure of Arabic clause in an Agr-based model. Papers and Studies in Constractive Linguistics, 34, 122-139.

Assiri, A. (2011). Arabic adjectival phrases: An Agree-based approach. Ph.D. Diss. University of Newfoundland.

Badawi, S., Carter, M. G., \& Gully, A. (2004). Modern written Arabic: A comprehensive grammar. London/New York: Routledge.

Boeckx, C. (2006). Minimalist essays. Amsterdam/Philadelphia, John Benjamins Company. http://dx.doi.org/10.1075/la.91

Chomsky, N. (1989). Some notes on economy of derivation and representation. MIT Working Papers in Linguistics, 10, 43-74.

Chomsky, N. (1995). The Minimalist program. Cambridge, MA: Massachusetts Institute of Technology.

Chomsky, N. (1999). Derivation by phase. MIT Working Papers in Linguistics.

Chomsky, N. (2000). Minimalist inquiries: The framework. In R. Martin, D. Michaels, \& J. Uriagereka (Eds.), Step by step: Essays on Minimalist syntax in honor of Howard Lasnik (pp. 9-155). Cambridge, MA: MIT Press.

Chomsky, N. (2004). Beyond explanatory adequacy. In A. Belletti (Ed.), Structures and beyond the category of syntactic structures (Vol. 3, pp. 104-131). Oxford: Oxford University Press.

Chomsky, N. (2005). Three factors in language design. Linguistic Inquiry, 36, 1-22. http://dx.doi.org/10.1162/0024389052993655

Chomsky, N. (2007). Approaching UG from below. In U. Auerland, \& H. M. Gartner (Eds.), Interfaces + recursion= language? Chomsky s minimalism and the view from syntax-semantics (pp. 1-29). Berlin: Mouton de Gruyter.

Chomsky, N. (2008). On phases. In C. O. R. Freidin, \& M. L. Zubizaretta (Eds.), Foundational issues in linguistic theory (pp. 133-166). Cambridge. MA: MIT Press. http://dx.doi.org/10.7551/mitpress/9780262062787.003.0007

Hasan, A. (1974). Annaîu al-waafi, [Compehensive syntax]. Dar al-maÀaarif, Cairo.

Horias, N. (2009). A Minimalist approach to agreement in Arabic. Newcastle Working Papers in Linguistics, 15.

Hornstein, N., Nunes, J., \& Grohmann, K. (2005). Understanding Minimalism. Cambridge: Cambridge University Press. http://dx.doi.org/10.1017/CBO9780511840678

Ibnaqeel, B. A. (1990). Explanation of Ibn Aukel. Daar al Khair. Cairo.

Jackendoff, R. (1990). On Larson's account of the double object construction. Linguistic Inquiry, 21, 427-454.

Larson, R. (1988). On the double object construction. Linguistic Inquiry, 19(3), 335-391.

Larson, R. (1990). Double objects revisited: Replay to Jackendoff. Linguistic Inquiry, 21, 589-632.

Lasnik, H. (2003). Minimalist investigation. Routledge, London and New York.

Mahfoudhi, A. (2002). Agreement lost, agreement regained: A Minimalist account of word order and agreement variation in Arabic. California Linguistic Notes, XXVII(2).

Mohammad, M. (1999). Checking and licencing inside DP in Palestinian Arabic. In E. Benmamoun (Ed.), Perspectives on Arabic Linguistics XII: Papers from the Twelfth Annual Symposium on Arabic Linguistics (pp. 27-44). Amsterdam, John Benjamins Publishing Company.

Radford, A. (1997a). Syntactic theory and the Structure of English. London Cambridge University Press. http://dx.doi.org/10.1017/CBO9781139166706

Radford, A. (1997b). Syntax: A Minimalist introduction. London, Cambridge University Press. http://dx.doi.org/10.1017/CBO9781139166898

Radford, A. (2004). Minimalist syntax: Exploring the structure of English. Cambridge, Cambridge University Press. http://dx.doi.org/10.1017/CBO9780511811319 
Radford, A. (2009). Analyzing English sentences: A Minimalist Approach. Cambridge, Cambridge University Press. http://dx.doi.org/10.1017/CBO9780511801617

Soltan, U. (2006). Standard Arabic subject-verb agreement asymmetry revisited in an Agree-based minimalist syntax. In C. Boeckx (Ed.), Agreement Systems. Amsterdam: John Benjamins.

Soltan, U. (2007). On Formal feature licensing in Minimalism: Aspects of standard Arabic Morphosyntax. Ph.D. dissertation, University of Maryland, College Park Press.

Ura, H. (2000). Local economy and generalized pied-piping. The Linguistic Review, 18.

\section{Copyrights}

Copyright for this article is retained by the author(s), with first publication rights granted to the journal.

This is an open-access article distributed under the terms and conditions of the Creative Commons Attribution license (http://creativecommons.org/licenses/by/3.0/). 